\title{
Open Method of Castration in an Indian Mongoose (Herpestes edwardsi): A Case Report
}

\author{
S. P. Nayak ${ }^{1 *}$,D. Parija ${ }^{1}$, A. K. Sahoo ${ }^{2}$ and S. M. Nanda ${ }^{3}$ \\ ${ }^{1}$ Department of Fisheries and Animal Resources Development, Govt. of Odisha, India, \\ ${ }^{2}$ Teaching Veterinary Clinical Complex, \\ ${ }^{3}$ Department of Veterinary and Animal Husbandry Extension, \\ College of Veterinary Science and Animal Husbandry, OUAT, Odisha, India
}

*Corresponding author

\section{A B S T R A C T}

\begin{tabular}{|l|}
\hline $\begin{array}{l}\text { Ke y w or d s } \\
\text { Castration, } \\
\text { Indian Mongoose }\end{array}$ \\
\hline Article Info \\
\hline $\begin{array}{l}\text { Accepted: } \\
\text { 15 December } 2019 \\
\text { Available Online: } \\
\text { 20 January 2020 }\end{array}$ \\
\hline
\end{tabular}

A pet Indian Mongoose was presented to TVCC, OUAT for castration. Castration was performed by open method using scrotal incision under general anaesthesia. This was done to control the violent nature of the animal. The surgical intervention was performed under general anaesthesia. Post operative care was advised for 7 days.

\section{Introduction}

Castration is the surgical technique for removal of testicles in male mongoose to prevent reproduction. Castration is generally performed to make the animal docile. There is also decrease in territorial marking behaviour. Mongoose belongs to the family Herpestidae and the genus Herpestes. Mongooses are fierce hunters as well as great pets. Males are very difficult to manage in groups. Therefore, neutering may be done to minimize the violent behaviour. Mainly male mongooses sexually mature at 12 to 16 weeks and can impregnate females.

\section{Case History}

A pet common Indian mongoose weighing about 800 grams and aged about 1.5 year was presented to the Teaching veterinary clinical complex, C.V.Sc \& A.H, Bhubaneswar on $10^{\text {th }}$ July, 2018. The animal was active and alert.

\section{Anaesthesia and monitoring}

The animal was fasted for 5 hours prior to surgery. General anaesthesia was obtained by injecting combination of xylazine hydrochloride $(4 \mathrm{mg} / \mathrm{kbw})$ and ketamine 
$(22 \mathrm{mg} / \mathrm{kbw}) \quad$ intramuscularly. This was sufficient to anesthetize the mongoose. However, Retting and Divers (1985) and Nath et al., (2006) suggested that atropine sulphate and ketamine hydrochloride was sufficient to anaesthetize animals of family Viverridae for restraint and handling. The animal was anaesthetized within 10 minute of anaesthesia administration and the heart rate along with eye reflexes of the patient was regularly monitored.

\section{Surgical procedure}

The animal was restrained in dorsal recumbency. The scrotal area was shaved and cleaned. The surgical site was scrubbed with

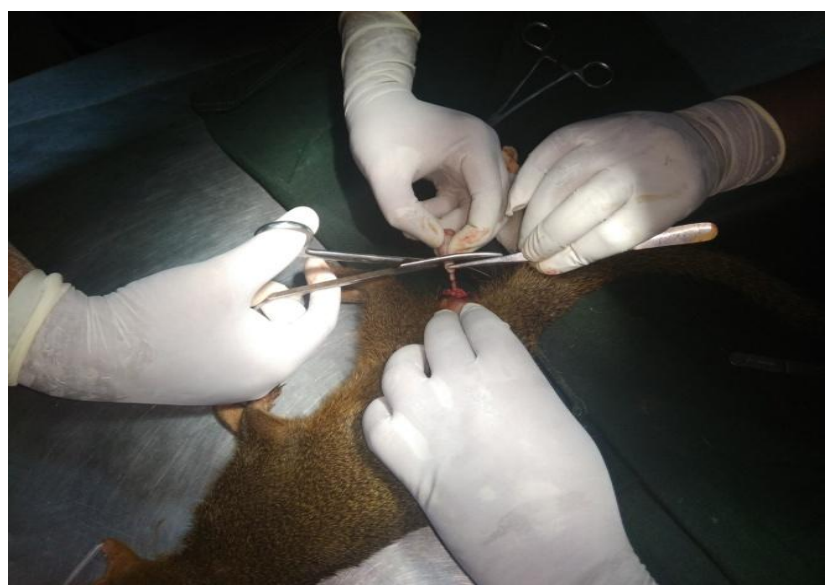

Figure.1 Open method of castration of Indian Mongoose

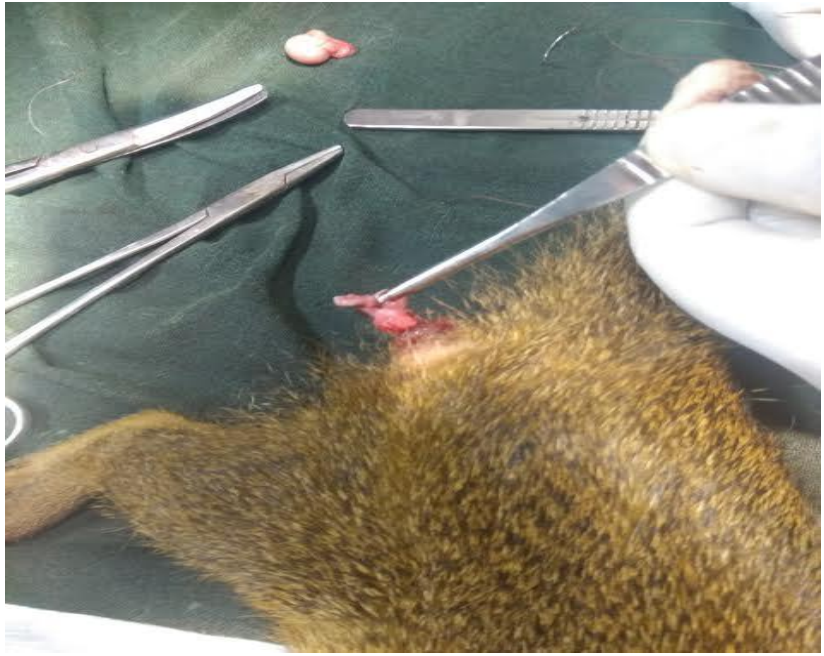

Figure.3 Ensuring proper haemostasis
7.5\% Povidone Iodine solution. An incision of $2 \mathrm{~cm}$ was made directly on the scrotum after securing the testicle. The tunica dartos was cut carefully leaving the tunica vaginalis intact. The testicle was squeezed out of the incision by application of digital pressure. A small haemostatic forceps was applied on the cord. Then, double ligature were applied proximal to haemostat on the spermatic cord with chromic catgut no 2-0. The knot was sufficiently tightened enough to ensure haemostasis and ligature retention, and the artery forceps was remove following severing the cord distal to it. The procedure was repeated for removal of other testicle. The skin incision was closed by using catgut on 2 0 in interrupted manner.

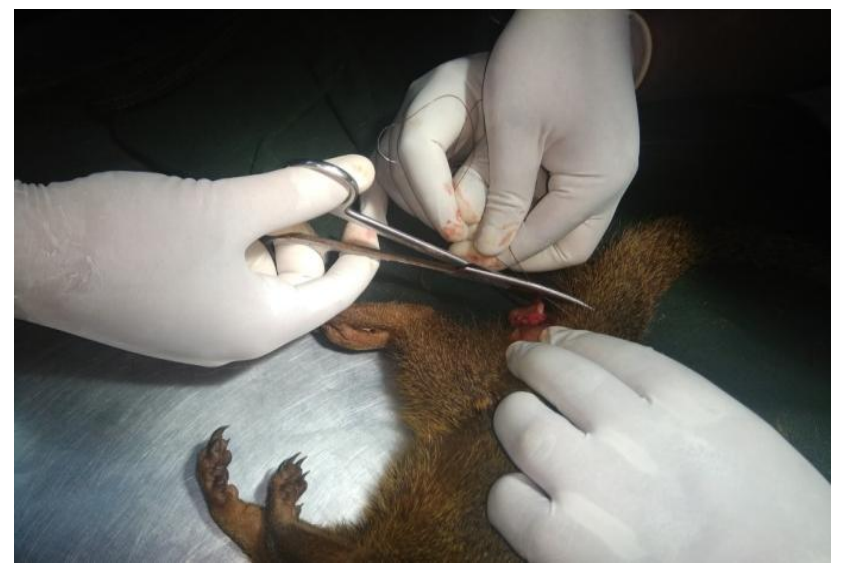

Figure.2 Checking the suture knot and removing extra suture material

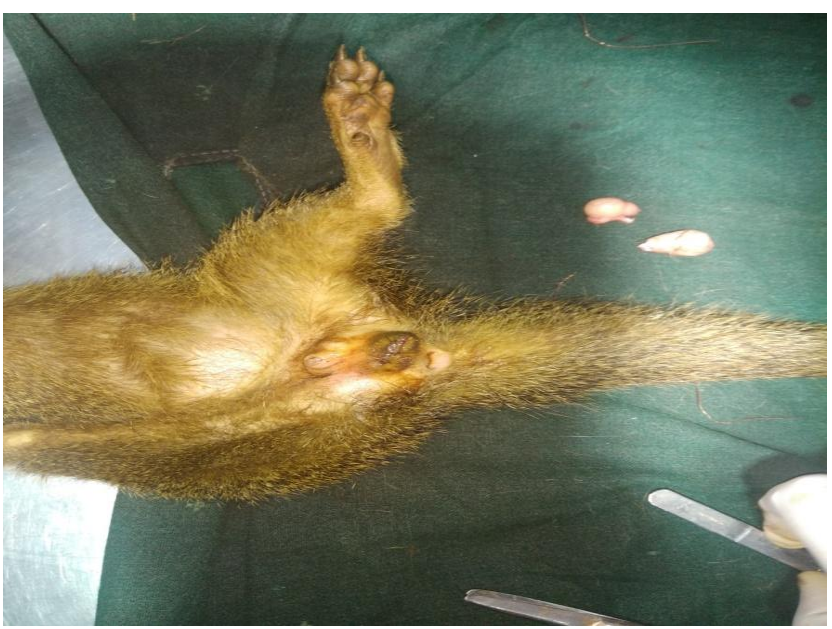

Figure.4 Closure of the incision site after removal of testicles 


\section{Post operative care}

As post operative care regular dressing was done with povidone iodine ointment till $7^{\text {th }}$ day. Enrofloxacin 50mg tablet (Ataxin $50 \mathrm{mg}$ ) was administered orally once daily for 5 days. Meloxicam oral suspension (Melonex oral suspension 10ml) was prescribed three drops orally daily for 3 days. Vit. B complex syrup (Polybion syrup 250ml) one tsf for 7 days was given. The surgical procedure followed in the present case was similar to described by Mithilesh (2017) and Nath et al., (2006). The antibiotics and supportive medications helped in minimizing the chances of post-operative complications and the animal recovered successfully.

\section{References}

Mithilesh Kumar, Contemporary Research In India. Vol. 7: Issue: 2 (2017)

Nath, I., T.K., Pattanaik, Bose, V.S.C., Das, M.R. and Panda, S.K. (2006). Z. Print.J. 21(11):2466.

Retting, T. and B.J. Divers (1986). Viverridae, 825-826

\section{How to cite this article:}

Nayak, S. P., D. Parija, A. K. Sahoo and Nanda, S. M. 2020. Open Method of Castration in an Indian Mongoose (Herpestes edwardsi): A Case Report. Int.J.Curr.Microbiol.App.Sci. 9(01): 1771-1773. doi: https://doi.org/10.20546/ijcmas.2020.901.198 